\title{
LA FILOSOFÍA DEL DERECHO DE JÜRGEN HABERMAS
}

or fin, después de abundantes anuncios, ve la luz la obra de Habermas dedicada
específicamente a los problemas iusfilosóficos ${ }^{1}$. Se trata de un grueso volumen
que en sus últimas cien páginas recoge estudios ya publicados con anterioridad
y que anticipaban algunas de las posturas que a lo largo del texto principal del
libro se desarrollan.
Como era de esperar, lo que Habermas hace es una aplicación de los postulados generales y ya conocidos de su teoría de la acción comunicativa a la problemática iusfilosófica y, particularmente, a la sempiterna cuestión de la validez de las normas jurídicas. Y en la respuestas a esta pregunta de Habermas va a aplicar siempre el esquema bipolar que ya se presenta en el propio título del libro: la validez se resuelve en una tensión entre facticidad o validez social y legitimidad o validez racional o comunicativa.

Las normas jurídicas han de poseer una dimensión fáctica, que tiene que ver con los dos aspectos interrelacionados de su cumplimiento habitual, por un lado, y de la coacción que lo respalda, por otro. Ahora bien, la función de integración social que al derecho le corresponde en sociedad complejas (en las que ya no bastan para cumplir esa función de orden e integradora los mitos o tabúes y las certezas incuestionadas que componen el mundo de la vida y en las que ha decaído también el respaldo religioso o metafísico de las normas como fundamento común y compartido) sólo puede cumplirse efectivamente si las normas poseen un elemento de legitimidad que rebasa su pura imposición coactiva y posibilita la mínima aceptación necesaria para su seguimiento. Esta legitimidad de las normas «es

${ }^{1}$ Jürgen Habermas, Faktizität und Geltung. Beiträge zur Diskurstheorie des Rechts und des demokratischen Rechtsstaats, Frankfurt M., Suhrkamp, 1992, 667 págs. Los números entre paréntesis en el texto remiten a páginas del libro. 
independiente de su imposición fáctica» (48) y depende del modo en que esas normas sean creadas. Son legítimas cuando sus destinatarios «pueden al mismo tiempo sentirse, en su conjunto, como autores racionales de esas normas» (52), es decir, cuando el procedimiento de creación de las normas reproduce el procedimiento argumentativo y consensual de la razón comunicativa; o dicho de otro modo, cuando se sigue el procedimiento democrático sin distorsiones. En suma, «la validez jurídica de una norma (...) significa ahora que ambas cosas se garantizan al mismo tiempo: tanto la legalidad de la conducta, en el sentido de un seguimiento generalizado de la norma, el cual en caso necesario puede ser forzado mediante sanciones, como la legitimidad de la regla misma, que hace posible un seguimiento de la norma basado en cada caso en una consideración positiva ante la ley» (49).

Queda así sentada una de las tesis centrales del libro y cabe ya a ese respecto plantear una primera duda: ¿es de índole fáctica o normativa la afirmación de que la función de integración social que el derecho ha de cumplir no se realizaría en un ordenamiento jurídico carente de legitimidad? Esa afirmación de Habermas puede entenderse de las dos maneras. Como afirmación empírica equivaldría a entender que allí donde los destinatarios de las normas no se sienten autores de las mismas, por no provenir éstas de un proceso legislativo de carácter democrático, esas normas no serán mayoritariamente cumplidas y ese ordenamiento no ejercerá la función de orden y coordinación de conductas que al derecho le corresponde. Pero esa tesis es fácilmente rebatible. En primer lugar, la evidente constatación de que los ordenamientos menos democráticos y más feroces han conseguido y consiguen imponer sus normas por encima de cualquier sentimiento de los sometidos a ellas. Las normas jurídicas del nazismo no provocaron precisamente el rechazo de los alemanes de la época, por mucho que en su creación ya no quedara ni rastro del proceder democrático. Y, en segundo lugar, si el dato determinante es que los destinatarios de las normas puedan «sentirse» autores de las mismas o de acuerdo con su contenido, esa aquiescencia puede inducirse con los medios y las técnicas del Estado moderno y alcanzarse incluso un grado de unanimidad que nunca se da en democracia. Sabido es que los dictadores de toda laya suelen sancionar con plebiscitos triunfantes sus más ambiciosas iniciativas legislativas.

Sólo queda, pues, entender que la afirmación de Habermas que comentamos posee un sentido normativo, es decir, que equivale a sostener que un derecho sólo cumple racionalmente su función integradora cuando es fruto del discurso racional, de un proceso participativo. Pero esta comprensión plantea varios problemas. Uno, que el tenor literal de las afirmaciones de Habermas más bien parece sugerir 
un carácter fáctico para su afirmación que comentamos. Y dos, que con ese entendimiento normativo nos damos de bruces con los mismos problemas de fundamentación que han afectado siempre a tesis como las iusnaturalistas: por qué sólo es válido el derecho que reúna unas ciertas condiciones (de contenido en el iusnaturalismo; procedimentales en Habermas) y, sobre todo, qué estatuto posee el derecho positivo que no cumpla con ellas. Y podría pensarse que el tono descriptivo de la tesis de Habermas, cuando sostiene que el derecho ilegítimo no sirve a la función de guiar las conductas e integrar la sociedad, es una forma de evitar las consecuencias normativas de sus premisas igualmente normativas: si la validez jurídica tiene una doble dimensión, fáctica y de legitimidad y si la primera no basta por sí sola, la conclusión sería que el ordenamiento al que le falte la dimensión de legitimidad no es derecho. Y por no decir esto acaba Habermas defendiendo algo cuya prueba es tanto o más difícil: que ese ordenamiento ni siquiera se cumpliría, que ni siquiera se daría en él la referida dimensión fáctica, cuestión que la historia desmiente a cada paso.

Cosa distinta sería interpretar que el derecho que posea solamente esa vertiente fáctica y que no sea fruto de la voluntad y el consenso de sus destinatarios cumple, al menos elementalmente, su función de orden e integración, bien como consecuencia de la fuerza, del miedo o, sobre todo, de la manipulación ideológica, pero que carece de las notas que permitirían calificarlo como racional, legítimo o justo. Y aquí es donde la doctrina que Habermas puede aportar sus mejores frutos, en cuanto teoría de la justicia más que, como él pretende, como teoría de la validez jurídica. Pues esto último sólo lo consigue, como ya hemos indicado, a costa de una tesis que no se atreve a formular en todo su alcance: entender que el derecho injusto, ilegítimo, no es válido. Habermas parece insinuar, por decirlo en términos de teoría del derecho, que ese derecho no puede ser eficaz. De ese modo parece sustraerse a los reproches habituales al iusnaturalismo. Pero queda a merced del desmentido de la historia, de la sociología y de una teoría del derecho que desde hace décadas sabe distinguir entre facticidad o eficacia, validez o positividad y justicia o legitimidad. Habermas, en cambio, habla de validez y facticidad para acabar entendiendo que ambas forman una síntesis cuya clave está en un tercer elemento que poco a poco va ocupando la plaza de ambas: la legitimidad.

Hasta aquí hablaba Habermas de lo que denomina el aspecto interno de la tensión entre facticidad y validez. A continuación se referirá al aspecto externo de esa relación, visto como la conexión entre los hechos sociales y la autocomprensión del derecho moderno. Según Habermas, la referida tensión entre facticidad y legitimidad 
de las normas jurídicas en su aspecto interno conlleva como consecuencia, en el aspecto externo, la necesidad de que el poder político, necesario para la imposición del derecho, se organice como poder legítimo, esto es, como Estado de Derecho. Y seguidamente se refiere a dos modos de desconocer esa necesaria dualidad entre facticidad y legitimidad en el aspecto externo: bien resaltando únicamente el componente fáctico, como hacen las doctrinas sociologistas, bien resaltando únicamente el aspecto de legitimidad, sin tener en cuenta los hechos, al modo de ciertas teorías de la justicia, como la de Rawls. Las primeras, ejemplificadas en Luhmann, operan una separación total del derecho respecto de la moral y la política y desaparece de ellas todo resto de «normativismo jurídico-racionalista», por lo que sólo permiten una lectura del derecho válido en clave positivista: la validez del derecho deriva únicamente del derecho válido (72). Las segundas descuidan la dimensión institucional y empírica del derecho. Ambas perspectivas serían unilaterales.

A continuación se enfrenta Habermas con la cuestión del fundamento último de validez de los sistemas jurídicos. Previamente ha ido mostrando cómo la visión positivista de la validez jurídica es insuficiente y errónea, por desconocer el componente de legitimidad o justicia inmanente a toda validez, por no tener en cuenta el «momento de indisponibilidad que se contiene en la pretensión de legitimidad del derecho» (96). Pues bien, al llegar aquí Habermas precisa de qué modo su filosofía del discurso proporciona una base última e irrebasable para todo ordenamiento jurídico que pueda pretenderse legítimo y, con ello, válido en toda su extensión. Y en esto radica también la aportación más novedosa de esta obra de Habermas, por comparación con sus anteriores referencias a esta materia. Sitúa ese fundamento en la preexistencia de un sistema de derechos, si bien no se debe perder de vista que Habermas no busca sentar una serie de postulados morales apriorísticos, sino reconstruir los presupuestos de racionalidad inmanentes al derecho moderno.

Una vez que el derecho moderno se ha autonomizado de la moral y del respaldo religioso o metafísico de sus normas, queda constituido como un ámbito abierto a la argumentación, a la acción comunicativa, que sólo puede basarse en el entendimiento como fuente de la legitimidad de las normas. De ese modo pueden, con la modernidad, realizarse para el derecho de los presupuestos argumentativos y consensuales inmanentes a toda pretensión de validez lingüísticamente formulada. Y para que realmente sea posible esa construcción discursiva y consensual de las normas jurídicas, los sujetos deben presuponerse recíprocamente como autónomos, reconociéndose ciertos derechos. «Como participantes en discursos racionales, 
los destinatarios del derecho han de poder examinar si la norma en cuestión halla o puede hallar el asentimiento de todos los posibles afectados. Con ello -continúa Habermas- la interrelación interna entre soberanía popular y derechos humanos consiste en que el sistema de derechos indica precisamente las condiciones bajo las que las formas comunicativas necesarias para una creación del derecho políticamente autónoma pueden, a su vez, ser jurídicamente institucionalizadas» (134).

Se presupone así la autonomía de los sujetos, tanto en lo público como en lo privado. Sin esa autonomía integral que los derechos humanos garantizan no sería posible el modo de ejercicio de la autonomía política que se traduce a través de la formación discursiva de opiniones y voluntades. Se trata de hacer posible un acuerdo que sea fruto de un proceso cuyas condiciones garanticen que el contenido de ese acuerdo, en cuanto resultante de «un entendimiento de los ciudadanos sobre las reglas de su convivencia», exprese el punto de vista del bien común y de las expectativas normativas ligadas a él (111). Por tanto, derecho objetivo y subjetivo se dan en «interna interdependencia» (135), sin que ninguno sea anterior al otro y sin que uno pueda darse sin el otro.

Nos movemos aquí en el terreno en que derecho y moral tienen puntos de coincidencia, pues, según Habermas, el derecho positivo está vinculado a la moral a través del componente de legitimidad de la validez jurídica, siendo esa relación de «complementariedad» y no de jerarquía (137). Moral y derecho tienen en común el que para ambos rige el principio discursivo, si bien el contexto del discurso moral es la humanidad entera y el del principio democrático, mediante el que se establece el derecho positivo válido, es una determinada comunidad (139).

Enumera Habermas esos derechos «que los ciudadanos se deben reconocer recíprocamente si quieren regular de modo legítimo su convivencia mediante el derecho positivo» (109). Son los derechos exigidos para hacer posible la efectiva realización del principio discursivo, base del procedimiento democrático y fundamento de la legitimidad (y, con ello, de la validez) de las normas resultantes. Ese sistema de derecho constituye los presupuestos «de los que los miembros de una comunidad jurídica moderna han de partir si quieren poder tener por legítimo su ordenamiento jurídico sin apoyarse para ello en fundamentos de tipo religioso o metafísico (...). Los derechos que en este experimento intelectual se reconstruyen son constitutivos para toda asociación de sujetos jurídicos libres e iguales» (166). Y tal sistema de derechos resulta de que «el medio jurídico como tal presupone derechos que definen el status de sujetos jurídicos como portadores de derechos» (151). 
Se presupone, en primer lugar, un margen de libertad de acción privada. Esos derechos exoneran al titular de la necesidad de dar cualquier explicación acerca de su esfera privada: el actor no necesita aportar fundamentos públicamente aceptables de su actuación en ese ámbito (153). Y no sólo se exige que exista esa esfera de la libertad subjetiva, sino también que sea igual para todos. Por otro lado, en cuanto a la esfera pública, «la idea de autolegislación de los ciudadanos exige que aquellos que están sometidos al derecho como destinatarios se puedan entender, al mismo tiempo, como autores del derecho» (153), lo cual se consigue a través de la institucionalización de procedimientos democráticos.

¿Cómo especifica Habermas esos derechos fundamentales que todo ordenamiento legítimo presupone y protege? Los divide en cinco grupos.

(1) «Derechos fundamentales que resultan de la conformación, políticamente autónoma, del derecho a la mayor medida posible de iguales libertades subjetivas de acción» (155).

Se trata del derecho de cada cual al mayor grado posible de igual libertad de acción subjetiva, sólo limitable para compatibilizarla con la libertad igual de los demás.

(2) «Derechos fundamentales que resultan de la conformación, políticamente autónoma, del status de miembro en una asociación voluntaria de sujetos jurídicos» (155).

Estos derechos derivan del dato de que, a diferencia de lo que ocurre con la moral, las normas jurídicas no regulan las interacciones en general entre los sujetos, sino las interacciones dentro de una concreta sociedad. Esto «se sigue ya del concepto de positividad del derecho» (157) y viene exigido por la necesidad de que los sometidos al derecho puedan apelar a una instancia que monopolice la violencia legítima. Es necesario, por tanto, que el ordenamiento diferencie entre miembros y no miembros de la comunidad jurídica, entre ciudadanos y extranjeros. Es decir, son necesarios los derechos de nacionalidad. Según Habermas, la necesidad de protección frente a la privación unilateral de esos derechos resulta «de la aplicación del principio discursivo» (158). Aquí podríamos plantearnos una duda sobre la coherencia de la construcción habermasiana: ¿no parece que el principio universalista que preside su teoría discursiva y su ética normativa casa mal con la defensa de las fronteras estatales y con la interpretación del interés general, clave legitimatoria de lo jurídico, como interés de una determinada comunidad nacional y, por tanto, 
no universalizable, sino, como máximo, generalizable para los miembros del concreto Estado de que se trate?

(3) «Derechos fundamentales que resultan de modo inmediato de la reclamabilidad de derechos y de la conformación, políticamente autónoma, de la protección jurídica individual» (156).

Se trata de los derechos que garantizan la vía jurídica, como el libre acceso a tribunales independientes y efectivos.

Explica Habermas que esos tres tipos de derechos surgen de la mera aplicación del «principio discursivo al medio jurídico como tal» (156), y que «no hay derecho legítimo sin esos derechos» (159). Pero puntualiza que no se trata de los derechos liberales clásicos, sino que se hallan a un superior nivel de abstracción. Más bien consisten en «principios jurídicos a los que el legislador constituyente se orienta» y que éste debe necesariamente considerar, «pues en estos principios se hace valer el sentido racionalizador de la forma jurídica como tal, que ya Hobbes y Rousseau acentuaron» (160). Por tanto, los derechos fundamentales clásicos del liberalismo (la dignidad humana, libertad, integridad de la vida y el cuerpo, propiedad, elección de profesión, inviolabilidad del domicilio, etc.) son «interpretaciones y configuraciones del derecho general de libertad» en el sentido del derecho a iguales libertades subjetivas mencionado en (1). El mismo significado tienen, respecto de (2), la prohibición de extradición, el derecho de asilo, el derecho a la nacionalidad, etc., e igual interpretación por relación a (3) cabe hacer de postulados como la irretroactividad, el non bis in idem, la prohibición de tribunales especiales, la garantía de la independencia judicial, etc. (159-160).

El siguiente derecho que Habermas menciona en su enumeración tiene que ver con los derechos fundamentales de carácter político, tendentes a hacer posible que los sujetos puedan alcanzar el rol de autores de su ordenamiento jurídico:

(4) «Derechos fundamentales a una participación, en condiciones de igualdad de oportunidades, en los procesos de formación de opiniones y voluntades en los que los ciudadanos ejercen su autonomía política y mediante los cuales sientan derecho legítimo» (156).

El fundamento de estos derechos políticos es claro: «con arreglo al principio discursivo pueden pretender validez precisamente aquellas normas que puedan hallar el asentimiento de todos los potenciales afectados, en la medida en que éstos tomen parte en discursos 
racionales» (161). Es esa participación discursiva en la producción de las normas lo que estos derechos políticos aseguran.

Aquí se detecta una tensión entre lo que son los presupuestos teóricos del principio discursivo y lo que es el ejercicio del derecho de autodeterminación y autolegislación por los sujetos. La pregunta que podríamos hacernos es la siguiente: ¿pueden discursivamente los sujetos decidir la eliminación de los principios o procedimientos que garantizan el ejercicio de su autonomía? La respuesta de Habermas sería que hay dos cosas que los sujetos no pueden eliminar: el principio discursivo, con los citados presupuestos en cuanto a la autonomía de los sujetos, y el medio jurídico, con los mencionados principios o derechos en abstracto que sirven como única vía para la articulación colectiva o intersubjetiva de aquella autonomía. Más adelante resaltará nuevamente que el sistema de derechos constituye un límite sustraído a la decisión mayoritaria, pues «los ciudadanos no pueden, en ejercicio de su autonomía política, atentar contra el sistema de derechos que constituye dicha autonomía» (221). Y si es el principio de soberanía popular el que garantiza la autoorganización de la sociedad, ese principio queda fuera de la disposición de esa sociedad: «la idea de soberanía popular remite, en su lectura procedimentalística, a las condiciones que en el marco social posibilitan la autoorganización de una comunidad pero que, a su vez, no están sin más a disposición de la voluntad de los ciudadanos» (366). Y aún insiste en que no quedan a disposición de la política «las condiciones que hacen posible la producción de derecho legítimo» (466).

Son los propios ciudadanos los que, en ejercicio de esa autonomía así garantizada, como legisladores constituyentes, en cada caso y época concreten el sistema de derechos. Por eso dice Habermas que «este sistema de derechos no está previamente prescrito al legislador constitucional como derecho natural» (163). «No existe «el» sistema de los derechos en su pureza trascendental», al margen del contexto histórico en que en cada ocasión se interpreta (163).

Estamos así ante el componente de historicidad que necesariamente relativiza las tesis habermasianas sobre el contenido de justicia de la validez jurídica. Pero de nuevo nos enfrentamos entre lo que son postulados normativos inmanentes o necesariamente derivados de toda comunicación lingüística (y en especial de todo dirimir discursivo y, por tanto, consensual, de pretensiones de validez normativa enfrentadas) y el grado posible de realización histórica de esos postulados. Sólo al final de un proceso filogenético y ontogenético que lleva a las sociedades y a los individuos a un estadio de maduración moral que se corresponde con el último nivel descrito en la gradación que Kohlberg establece, parece que se dan las condiciones para que se hagan efectivos en la convivencia esos postulados 
normativos de la ética discursiva que son (y en todo tiempo han sido) presupuestos como válidos al usar del lenguaje. Pero dos problemas pueden aparecer aquí. Por una parte, si entendemos que existen contenidos normativos (libertad, igualdad de todo sujeto capaz de lenguaje, de todo interlocutor potencial) que, en cuanto presupuestos en el lenguaje han sido válidos desde siempre (desde que existe lenguaje $\mathrm{y}$, con ello, sociedad) aunque sólo en un determinado estadio del proceso civilizatorio hayan podido descubrirse, estamos ante tesis que podrían ser objeto de las críticas habituales al iusnaturalismo. Pero si entendemos que sólo en un determinado momento histórico de la articulación de las relaciones sociales, sólo en la época moderna, se reconstruyen esos postulados normativos como inmanentes a las instituciones que en esa época se imponen mediante la comunicación lingüística, se introduce un peligroso elemento relativístico que puede fundamentar acusaciones de etnocentrismo y similares y que nos aproxima a posturas como la de Rorty, que Habermas ha rechazado en trabajos anteriores. En el marco de esa problemática habrá que situar las afirmaciones de Habermas de que los referidos derechos, que «son condiciones necesarias que posibilitan el ejercicio de la autonomía política», «no pueden limitar la soberanía del legislador, aunque no están a disposición de éste»; o que «cada ejercicio de autonomía política significa al mismo tiempo una interpretación y conformación por el legislador histórico de esos derechos nunca saciados» (162); o que «los capítulos de derechos fundamentales de las constituciones históricas se pueden entender como lecturas, contextualmente dependientes, del mismo sistema de derechos» (162) y que «es en una determinada interpretación constituyente como esos derechos vienen a la conciencia», (163). Es la tensión en la búsqueda por Habermas de un punto medio entre cognitivismo e historicidad, que acaba desembocando en una síntesis un tanto equivocada, pues siempre podemos preguntarnos qué queda de esos derechos si de los mismos sólo caben lecturas históricas y condicionadas por el contexto y, sobre todo, a partir de qué contenidos un texto constitucional dejaría de poder interpretarse como particular lectura y garantía contextualmente dependiente de ese sistema de derechos y podría entenderse el correspondiente ordenamiento jurídico como ilegítimo y, por extensión, inválido. ¿Lo eran las constituciones modernas que negaban el voto a la mujer? ¿Lo seguiría siendo una constitución actual que aún lo negara?

Hay en Habermas una tensión también entre el componente constructivo y el reconstructivo. O dicho de otra forma, entre la revelación de los postulados inmanentes a toda argumentación, a toda acción lingüística, base de su teoría de la acción comunicativa, y la reconstrucción de los presupuestos inmanentes a cierta institución 
o manifestación social histórica, como es el caso del derecho moderno en las páginas que estamos comentando. La tesis sería que en el derecho moderno toman cuerpo y se institucionalizan, se constituyen en fundamento, precisamente aquellos presupuestos generales del discurso. Si nos mantenemos a un nivel de gran abstracción esto puede sonar verosímil. Pero en cuanto descendemos a la gran variedad de formas y contenidos de los ordenamientos modernos y a la diversidad de concepciones de los derechos fundamentales que pueden invocar para sí la condición de legítimas y explicables interpretaciones del sistema de derechos que propone Habermas, nos encontramos con que o precisamos más el criterio de legitimidad (validez), de modo que podamos excluir de la condición de derecho válido gran parte de los ordenamientos jurídicos que en la edad moderna han sido o rigen aún, $\mathrm{o}$, de lo contrario, el criterio de legitimidad que se buscaba se disuelve en una lista de fórmulas vacías. Habermas, una vez más, no nos revela por completo la clave del dilema: «tras más de doscientos años de desarrollo constitucional europeo disponemos de modelos suficientes que pueden guiar una reconstrucción generalizadora de aquella comprensión que necesariamente guía la praxis intersubjetiva de una autolegislación llevada a cabo con los medios del derecho positivo» (163). Nuevamente podríamos preguntar: ¿se toman todos esos modelos para reconstruir los presupuestos comunes o se procede selectivamente, buscando aquellos modelos que reflejen ciertos presupuestos? En el primer caso, la reconstrucción posiblemente no aporte más que una imagen de contingencia histórica y de heterogeneidad difícilmente reductible; en el segundo, el proceder ya no sería reconstructivo, sino predeterminado por un criterio previo de carácter ahistórico.

Y para colmo del desconcierto, el elemento social o fáctico aparece también aquí para oscurecer aún más el panorama y hacernos pensar que al relativismo histórico se suma un cierto relativismo o condicionamiento sociológico: «las instituciones jurídicas de la libertad decaen sin las iniciativas de una población acostumbrada a la libertad. Su espontaneidad -continúa Habermas- no puede forzarse mediante el derecho; se regenera a partir de tradiciones de libertad y se contiene en las relaciones asociativas de una cultura política liberal» (165). A las dificultades para que los postulados de justicia que derivan de la ética cognitivista habermasiana puedan ser conocidos e incorporados a los ordenamientos de un determinado período histórico se suma ahora la dificultad de que ese derecho que los incorpora sea efectivo allí donde la población no está acostumbrada a ese derecho de la libertad. Esto último puede acabar ya en una perfecta circularidad del razonamiento, pues estaríamos ante ordenamientos legítimos que no son eficaces, lo cual difícilmente encaja en una teoría 
como ésta, que sienta como base de la legitimidad del ordenamiento el asentimiento de los destinatarios de sus normas.

En último lugar menciona Habermas, como derechos derivados de los mencionados de (1) a (4),

(5) «Derechos fundamentales a unas condiciones de vida que estén social, técnica y ecológicamente aseguradas en la medida respectivamente necesaria para un aprovechamiento, en condiciones de igualdad de oportunidades, de los derechos humanos mencionados en (1) a (4)» (157).

En el capítulo siguiente, cuarto, Habermas se interroga sobre la legitimación del poder político. Insiste en que es el sistema de derechos que hemos mencionado el que funda la necesidad del derecho objetivo y del poder político estatal como medio para la imposición $\mathrm{y}$ protección de esos derechos. Se trata de «implicaciones jurídico-objetivas que se contienen in nuce en los derechos subjetivos» (168). «Hasta la más simple legislación debe ser entendida como concreción del sistema de derechos conformado como Constitución» (191). La unión sustancial entre moral y derecho en ningún momento se diluye. Y hasta el sentido del procedimiento democrático proviene o está ya implícito en el sistema de los derechos (229). Y lo que ese sistema de derechos demanda no es la mera existencia de un poder político y un Estado, sino del Estado de Derecho y de una política sometida a las leyes emanadas de la soberanía popular. «No es la forma jurídica como tal lo que legitima el ejercicio de la dominación política, sino únicamente la vinculación al derecho legítimamente establecido». Este es únicamente el que «puede ser racionalmente aceptado por todos en un proceso de formación discursiva de la opinión y la voluntad» (169). En ese marco, la soberanía popular no se identifica con un grupo físico de personas, sino con un poder que circula comunicativamente y vincula al aparato administrativo del Estado. Es el derecho el instrumento mediante el que ese poder comunicativo se transmite al sistema administrativo, que se rige por un código de poder. De ahí que el Estado de Derecho se caracterice por la prioridad que ese poder comunicativo posee frente a otros poderes o intereses de grupos o personas. El procedimiento democrático «institucionaliza las formas comunicativas necesarias para una formación racional de la voluntad política» (221), y la «bisagra» entre el sistema de derechos y la construcción de un Estado democrático de Derecho la forma el principio de soberanía popular, en su interpretación discursiva.

Pese al vínculo entre moral y derecho, en cuanto presididos en última instancia por idéntico principio discursivo, el discurso jurídico y el moral tienen, según Habermas, diferente implantación. El 
discurso moral se dirige a un auditorio universal y trata únicamente de intereses perfectamente universalizables, mientras que el jurídico se inserta en un concreto marco estatal y social. Esto significa que el discurso jurídico no sólo está abierto a consideraciones morales, sino también a otras de carácter pragmático (relativas a estrategias o medios para fines preestablecidos) y ético (referidas a los fines a compartir en un determinado colectivo o grupo, como pueda ser un Estado nacional). Por tanto, las razones que respaldan la validez jurídica de una norma no tienen por qué ser únicamente razones morales, es decir, razones de justicia referidas a «si la correspondiente praxis es buena para todos en la misma medida» (220). La validez de las razones pragmáticas y éticas es contextual y relativa, mientras que sólo las razones morales poseen validez universal.

Se expresan nuevamente con esa diferenciación la tensión entre los requerimientos de universalidad, propios de todo enunciado normativo que se pretenda discursivamente racional, y la dependencia del discurso respecto de un determinado contexto social e histórico. Es el problema de si las razones que hacen válida y justa una norma son las razones del interés general dentro del concreto Estado en que se legisla (legislación en la que democráticamente participan todos los ciudadanos de ese Estado) o si esa justicia ha de tener alcance universal, de modo que no pueda verse como justo y válido el derecho de un Estado que en interés de sus ciudadanos explote o discrimine a los ciudadanos de otros Estados, ciudadanos que no participan en el proceso legislativo. Una norma habrá sido democráticamente aprobada cuando todos los ciudadanos de ese Estado hayan podido participar en su elaboración o puedan estar de acuerdo con su contenido, por expresar el interés general dentro de ese Estado. Y según Habermas, lo que se asume en el discurso moral, universalista, es que «una norma sólo es justa si todos pueden querer que esa norma sea seguida por cada uno en situaciones similares», por lo que se puede decir que «en el discurso moral se alarga la perspectiva etnocéntrica de un determinado colectivo a la perspectiva abarcadora de una comunidad de comunicación ilimitada, cuyos miembros se colocan en la situación y la comprensión del mundo y de sí mismo propia de cada uno y practican una asunción ideal de roles» (200). Pero es evidente que en esos dos supuestos el «todos» que hemos respectivamente subrayado tiene alcance distinto. Y el problema que aquí se plantea es si se debe considerar ilegítima e inválida por injusta una norma que cuente con el asentimiento libre y reflexivo de todos los ciudadanos de un Estado pero que (por ejemplo por versar sobre intereses enfrentados entre Estados) en ningún caso pueda contar con el respaldo general, al margen de fronteras, que exige el discurso moral. Si se afirma que el discurso moral prevalece, 
la salida más lógica para esta teoría sería entender que la restricción del proceder democrático al seno de cada uno de los Estados choca con el principio de universalidad que convierte en racionales y justas las normas. Si, por contra, se entiende que la norma estatal es válida, aunque no sea universalizable por no poder gozar de un hipotético consenso universal, el principio democrático perdería el fundamento universalista que la ética discursiva pretende proporcionarle.

Habermas trata, una vez más, de salvar el dilema con una salida intermedia: los resultados del discurso ético-político «deben ser al menos compatibles con los postulados morales», de modo que, diríamos nosotros, una resolución estatal discriminatoria con otros Estados o ciudadanos (por ejemplo, de carácter racista) sería rechazable en su validez aunque fuera democráticamente creada. En el discurso moral se exige dejar de lado todo contexto normativo contingente; la voluntad que se exige es una voluntad autónoma que se determina racionalmente, al margen de intereses o valoraciones ligados a un marco dado, por encima de las formas de vida y las tradiciones forjadoras de identidades sociales.

La cuestión reaparece en un capítulo posterior cuando Habermas contrapone su concepción discursiva de la democracia a las ideas comunitaristas. La diferencia estribaría en que para los comunitaristas la cuestión de la legitimidad de las normas se limita al aspecto ético, sin dejar presencia para la dimensión universalista del discurso moral. Es decir, lo que legitima a las normas de una comunidad, desde ese punto de vista, es que sean las normas mejores para regirla con arreglo al criterio autoidentificatorio de esa comunidad, a sus señas de identidad, a sus tradiciones e intereses. Frente a esa postura, señala Habermas la prioridad del discurso moral dentro de la formación democrática de la voluntad que legitima las leyes: «preferencia tiene la cuestión de cómo una materia puede ser regulada en igual interés de todos. La creación de normas está primariamente bajo el punto de vista de la justicia y se mide por principios que dicen que es igualmente bueno para todos. A diferencia de las cuestiones éticas, las cuestiones de justicia no quedan referidas a un determinado colectivo y su forma de vida. El derecho políticamente establecido en una concreta comunidad jurídica debe, si ha de ser legítimo, al menos estar en consonancia con postulados morales que pretenden validez también más allá de la comunidad jurídica». Y finaliza Habermas este razonamiento proponiendo una vez más una síntesis entre contrarios que se nos antoja un tanto artificiosa: «Lo que el modo deliberativo de la praxis legislativa ha de procurar no es sólo la validez ética de las leyes. Más bien se puede comprender la compleja pretensión de validez de las normas jurídicas como la pretensión de, por un lado, tomar en cuenta en relación con el bien común 
los intereses parciales que se defienden estratégicamente y, por otro lado, buscar principios universalistas de justicia en el horizonte de una determinada forma de vida imbuida de constelaciones valorativas particulares» (344).

Y se ayuda Habermas, para salir del dilema, de una diferenciación de las materias sobre las que puede versar cada uno de esos discursos, regidos por lógicas distintas, contextual la una y universalista la otra. Son supuestos de discurso moral en el derecho los referidos a cuestiones penales como el aborto o la prescripción de los delitos, de derecho procesal, como la prohibición de ciertos medios de prueba, o cuestiones de política social, derecho fiscal, organización del sistema de sanidad o de enseñanza, etc., que afectan a la distribución de la riqueza social o a las oportunidades vitales. En cambio, son cuestiones éticas (para las que no se requiere ese discurso moral al que subyace un «test de generalización», sino un discurso relativo a «procesos de autocomprensión colectiva» dentro de una determinada Lebensform) las relativas a asuntos como los ecológicos relacionados con la protección del medio o los animales, la planificación del tráfico y del urbanismo, las cuestiones de política de inmigración, de protección de minorías culturales o étnicas, etc. (204). El comentario que a propósito de esta enumeración se nos ocurre es que resulta un tanto complicado comprender su lógica interna, entender, por ejemplo, por qué los problemas ecológicos o de inmigración requieren un discurso menos exigente en cuanto a las condiciones de aceptabilidad de sus resultados que el relativo a la fijación del plazo de prescripción de los delitos.

La legitimación del derecho sobre la base de que constituye la institucionalización de los procedimientos del discurso racional, le sirve también a Habermas para explicar la superioridad de la Constitución sobre la ley. Se debe a que es en la Constitución donde se establece el procedimiento discursivo de producción de la ley.

Seguidamente extiende Habermas su teoría jurídica al discurso de aplicación del derecho. Aquí la tensión entre facticidad y validez se manifiesta como tensión entre seguridad jurídica y búsqueda de la justicia para las decisiones. Como argumento en favor de la sumisión a las normas jurídicas manifiesta Habermas no sólo el de la seguridad jurídica. Cuando, además, esas normas son legítimas, es decir, fruto de la institucionalización del proceder discursivo racional, «merecen obediencia y deben en cada ocasión ser seguidas también en consideración a la propia ley» (242). Por todo lo dicho, afirma Habermas que las decisiones judiciales han de satisfacer simultáneamente un doble requisito: consistencia con el ordenamiento y aceptabilidad racional (243). Acoge la distinción entre justificación interna y externa y explica que «el problema de la racionalidad de la 
jurisprudencia consiste en cómo puede la aplicación de un derecho contingentemente surgido ser realizada de modo internamente consistente y externamente fundada de modo racional, a fin de garantizar simultáneamente seguridad jurídica y justicia» (244).

Se requiere, por tanto, que las decisiones judiciales se basen en normas legítimas y que, al mismo tiempo, estén racionalmente justificadas para el caso. Nuevamente encontramos a Habermas sumergido en una de las sempiternas alternativas de la filosofía jurídica, en este caso el dilema entre generalidad de la norma y justicia del caso. Y antes incluso de desarrollar la salida que para el dilema nos propone, podemos adelantar una posible objeción a su planteamiento. ¿No se puede entender que la pretensión de legitimidad queda agotada en la norma positiva democráticamente creada, de modo que nunca se pueda considerar legítimo el apartamiento por el juez del tenor de la norma positiva, sea cual sea el argumento que utilice para justificar esa desviación, y dado que el juez carece de legitimación democrática? ¿No habría que limitarse a entender que el discurso del juez ha de poseer únicamente lo que podríamos llamar una racionalidad residual, es decir, operante tan sólo dentro del margen dejado por el tenor literal de las normas positivas? Esto equivale a hacer prevalecer, en cuanto al discurso del juez, el elemento de seguridad jurídica sobre el elemento de aceptabilidad racional de la decisión en sí, lo cual no constituye una merma de la racionalidad global cuando se trate de la aplicación de normas positivas de origen democrático y discursivo: esa consistencia de la decisión judicial con el ordenamiento, con las normas positivas, no sería sino sumisión a las decisiones discursivamente fundadas y, por tanto, racionales; además, esto evita lo que podríamos llamar conflicto de racionalidades: el conflicto entre la racionalidad discursiva de la norma y la racionalidad del juez, conflicto que ha de resolverse en favor de la primera, pues mientras la norma legal democrática es fruto de la efectiva articulación de la racionalidad comunicativa como racionalidad intersubjetiva, las valoraciones del juez, por mucho que se pretendan racionales y universalizables, no llevan el aval de ser resultado de un procedimiento discursivo efectivamente desenvuelto y, con ello, fruto del interés general y la neutralidad.

Para Habermas, que una norma sea «válida prima facie» significa únicamente que ha sido imparcialmente fundada y que su aplicación imparcial conduce a la decisión válida de un caso. Pero «la validez de la norma no garantiza aún su justicia en el caso particular» (266). A este propósito distingue Habermas, siguiendo a Klaus Günther, entre discurso fundamentador y discurso de aplicación de normas. El primero es el que sirve a la creación de las normas jurídicas válidas; en el discurso de aplicación, en cambio, «no se trata de 
la validez, sino de la adecuada referencia de una norma a una situación» (267). Aquí es donde Habermas suscribe la tesis de la única decisión correcta. Ante cada situación sólo hay una decisión correcta, por mucho que puedan ser varias las normas aplicables o las interpretaciones que vengan al caso. La adecuada ponderación discursiva de la situación y sus pormenores servirá para concretar la norma que mejor encaje en esa situación. Ciertamente el juez está vinculado a las normas jurídicas y, en cuanto éstas son legítimas, queda liberado de plantearse cuestiones relativas a su fundamentación, es decir, no es el discurso fundamentador el que aquí entra en juego. Pero, según Günther y Habermas, los jueces no pueden evitar el «juicio reconstructivo» de la norma ante la situación dada, juicio presidido por la idea de consistencia y sistema.

Se trata de evitar la imagen de que varias normas entran en conflicto y contradicción para un único caso o una misma situación. Esa colisión entre normas sólo puede evitarse en el presupuesto de que «todas las normas válidas forman, en última instancia, un sistema coherente que permite para cada situación de aplicación una única respuesta correcta» (285). Es la corrección de esa respuesta y, con ello, la de la decisión, la que se dirime en el discurso de aplicación. Ese discurso opera al mismo tiempo como garantía última de la coherencia del sistema jurídico puesto que, llegados a ese momento práctico y decisorio, vemos que no cabe ya que existan contradicciones entre normas: la correcta interpretación de la situación permitirá entender que sólo una única norma, y ninguna más, es la aplicable. Queda, con esa visión del sistema, excluida la existencia de normas contradictorias, es decir, de contradicciones dentro del sistema. Y ello porque se entiende que el proceso de concreción de las normas ante cada caso y situación de forma parte de la conformación última de esas normas y ese sistema, de modo que la clave estará, por ejemplo, en que nunca un caso se va a resolver contradictoriamente, es decir, aplicando simultáneamente normas que se contradicen. Las normas serán lo que digan para cada caso, y entre normas prima facie contradictorias, sólo una se entenderá aplicable y concretada para esa situación, por lo que, a fin de cuentas, el sistema no contiene contradicciones.

Esa división del discurso jurídico en fundamentador y de aplicación es la que sirve también a Habermas para criticar la tesis de Alexy de que el discurso jurídico es un caso especial del discurso práctico general. Según Habermas, equiparar todo discurso jurídico, incluida la argumentación tendente a la aplicación del derecho, al discurso práctico general, equivale a entender que en la aplicación de las normas sigue abierta la cuestión de la fundamentación o racionalidad de las mismas, mientras que el modelo de discurso jurídico 
que Günther y Habermas proponen permite descargar al juez de los problemas de fundamentación de la norma que aplica. La racionalidad de su decisión ya no dependerá del fundamento racional de esa norma, cuestión que ya estará resuelta en un discurso distinto y anterior, sino de la interpretación discursiva de la situación y de la concreción de la norma más apta, que será la norma de ese preciso caso. La diferencia principal con Alexy posiblemente estribe en que éste descarta la tesis de la única respuesta correcta y entiende que el procedimiento discursivo racional sirve únicamente a los efectos de excluir las decisiones incorrectas por irracionales.

Recalca Habermas que esa búsqueda por el juez de la respuesta correcta ha de acontecer de modo discursivo y, por tanto, intersubjetivo. Y la teoría del discurso hace depender la aceptabilidad de la decisión «no de la calidad de los argumentos, sino de la estructura del proceso argumentativo» (277). El juez, dice Habermas, ha de concebir su labor de «interpretación constructiva» como una «empresa colectiva» que se desarrolla sobre el trasfondo de la comunicación pública entre los ciudadanos (274), actuando en cada tiempo «los estándars acreditados en la profesión» como garantía de la objetividad y aceptabilidad intersubjetiva del juicio (275). No se excluye la falibilidad de las razones disponibles y aceptadas en cada momento, pero la argumentación lleva a resultados correctos «cuando las razones se condensan, sobre el horizonte de asunciones de fondo que permanecen incuestionadas, en un todo coherente que permite que recaiga un acuerdo libre de coacción en tomo a la aceptabilidad de la pretensión de validez que se discute» (278).

Ante la posible objeción que haga referencia a un eventual daño para la seguridad jurídica como consecuencia de ese relevante papel del juez, puntualiza Habermas que su teoría conduce a una manera distinta de entender tal valor. Se tratará de una seguridad jurídica dependiente del procedimiento. Para los sujetos la seguridad jurídica deriva de la institucionalización como proceso jurídico de un procedimiento discursivo que permita a cada afectado exponer las razones relevantes y sólo las razones relevantes de cara a la aclaración de los hechos y el derecho (270). De ahí la importancia del derecho procesal, el cual asegura el marco temporal, social y objetivo para el desarrollo libre de un proceso comunicativo que sigue la lógica del discurso de aplicación.

Habermas lleva sus consideraciones metodológicas a la jurisprudencia constitucional y se plantea el debatido tema de cuál es su papel en el ordenamiento jurídico y en qué medida suplantan o complementan estos tribunales al legislador. Quiere Habermas salvar el esquema de la separación de poderes y mostrar que, frente a la posible dimensión creativa de derecho de las cortes constitucionales, la 
única fuente de legitimidad para el derecho proviene de su creación por un poder legislativo de base democrática. «Puesto que la praxis decisoria de los jueces está sometida a la ley y al derecho, la racionalidad de la jurisprudencia remite a la legitimidad del derecho válido. Ésta -continúa Habermas- depende a su vez de la racionalidad de un proceso legislativo que, bajo las condiciones de la división jurídico-estatal de poderes, no queda a disposición de los órganos de la aplicación jurídica» (292).

Al referirse, con esas premisas, a la labor de los tribunales constitucionales, se concentra Habermas en su misión de defensa de los derechos fundamentales. La clave estará en este caso en el estatuto que se atribuya a las declaraciones constitucionales en que tales derechos se formulan, pues, según se conciban como auténticas normas jurídicas o como valores, cambiará el papel y la función del tribunal constitucional que los aplica. La tesis de Habermas sera que los derechos fundamentales son principios que, a efectos de su aplicación, en nada se diferencian de cualesquiera otras normas jurídicas. Niega que se trate de valores, ya sea en el sentido en que entiende los valores de la ética material de valores, seguida por cierta jurisprudencia constitucional alemana, ya en el sentido de los mandatos de optimización de que habla Alexy.

¿En qué consiste la diferencia, según Habermas, entre principios, entendidos como normas y valores? Las normas tienen carácter deontológico; son válidas o inválidas y obligan o no obligan, sin grados intermedios ni excepción, y no pueden entrar en conflicto entre sí para un mismo caso, de modo que cada una se aplique hasta cierto punto o en cierta medida; forman un sistema coherente. Por contra, los valores tienen sentido teleológico; no rigen de modo absoluto e incondicionado, sino relativo; indican preferencias compartidas y la prioridad de ciertos bienes en determinado grupo o colectivo, bienes que se hacen objeto de acciones finalísticas y que pueden ser objeto de prioridad o consecución en medida variable; los valores se contradicen y compiten entre sí por la preeminencia en cada caso y queda a quien decide la función de precisar esa preferencia en cada ocasión. Esta concepción de los principios como normas que sólo pueden ser válidas o inválidas, no válidas en medida variable y relativa, que obligan de modo absoluto, como cualquier otra norma, es posible debido al concepto de norma jurídica que maneja Habermas y que reseñé en páginas anteriores. Las normas que forman parte de un sistema que sólo en la aplicación a los casos se perfila y se perfecciona definitivamente, de modo que las normas sólo hallan su lugar en el sistema a la luz de cada situación, según que se apliquen a él o no se apliquen. «Distintas normas no pueden contradecirse entre sí cuando pretenden validez para el mismo círculo de destinatarios; han de integrar un 
todo coherente, es decir, formar un sistema. Distintos valores compiten por la preferencia; en la medida en que encuentran reconocimiento intersubjetivo en una cultura o una forma de vida, forman una configuración flexible y con abundantes tensiones» (311).

Varía totalmente la imagen de los derechos fundamentales según se entiendan, en ese sentido, como normas o valores, en ese sentido. «Como normas, regulan una materia en igual interés de todos; como valores, forman, en la configuración con otros valores, un orden simbólico en el que expresan la identidad y la forma de vida de una comunidad jurídica particular» (312). Concebir los derechos fundamentales de ese modo significa entender que el tribunal constitucional, al resolver los casos relativos a ellos, interpreta y aplica normas y realiza un supuesto más del discurso de aplicación, sin invadir el discurso fundamentador y la actividad legislativa. La Constitución no se disuelve en un orden de valores para cuya fijación el tribunal constitucional tenga la última palabra. No se trataría de ponderar o sopesar valores, sino de aplicar la norma que mejor se adapte a la situación que se enjuicia. La doctrina metodológica de Habermas y Günther despliega aquí su virtualidad. En caso de conflicto entre dos principios, así vistos como normas, no se trata de decidir en qué medida el respectivo valor puede realizarse, sino de «hallar, de entre las normas prima facie aplicables, aquella que mejor se adecue a una situación de aplicación descrita del modo más completo y bajo todos los puntos de vista relevantes» (317).

Sumando las consideraciones de Habermas referentes a la legitimación discursiva y procedimental de las normas jurídicas y su teoría del discurso de aplicación de las mismas, resulta también su tesis sobre el modo más adecuado de explicar la función de los tribunales constitucionales. Puesto que «sólo las condiciones procedimentales de la génesis democrática de las leyes aseguran la legitimidad del derecho establecido» (320), los tribunales constitucionales han de velar por el sistema de derechos que es fundamento y condición de posibilidad de la efectividad de ese procedimiento discursivo de creación del derecho. «El tribunal constitucional debe salvaguardar aquel sistema de derechos que posibilita la autonomía privada y pública de los ciudadanos del Estado (...). Por ello, el tribunal constitucional ha de examinar los contenidos de las normas discutidas por referencia a los presupuestos comunicativos y las condiciones procedimentales del proceso legislativo democrático» (321). Es ese modo procedimental de concebir hasta la misma Constitución el que presta a la jurisprudencia constitucional su legitimación democrática. $Y$, dentro de ese marco, justifica Habermas un fuerte activismo de los tribunales constitucionales: «Cuando se concibe la Constitución como interpretación y conformación de un sistema de derechos que hace valer la 
interna conexión entre autonomía privada y pública, no será dañosa, sino que puede incluso venir normativamente exigida, una jurisprudencia constitucional ofensiva en casos en los que se trate de la imposición del procedimiento democrático y de la forma deliberativa en la formación de la opinión y voluntad políticas» (340).

El paso siguiente al que se ve abocada esta teoría de Habermas consiste en proporcionar una teoría de la democracia. Aquí está una de las tesis fundamentales que Habermas viene repitiendo, la idea de que el procedimiento democrático del moderno Estado de Derecho equivale a la institucionalización, bajo forma y garantía jurídica, de las exigencias de la razón práctica idealmente inmanentes a la praxis comunicativa que posibilita la existencia social. De ahí que las resoluciones democráticas vayan avaladas por una «presunción de racionalidad» (368), resultante de ser el proceder democrático reflejo de la racionalidad discursiva.

Habermas es consciente del riesgo de que sus tesis se tilden de «confusión esencialista» (392), esto es, que se interprete que todo acuerdo democrático que en una sociedad y un momento dados se tome significa la realización de una racionalidad intemporal y perfecta. Y puntualiza que no es lo mismo la presuposición en toda acción comunicativa de una comunidad ideal de entendimiento, que pensar que ya es ideal y racional la comunidad efectiva en que acontece el concreto entendimiento, el acuerdo democrático de que se trate. Ese presupuesto es un «presupuesto contrafáctico» (392) que hace que las pretensiones de validez «trasciendan» la «provincialidad» del contexto particular en que inevitablemente se plantean (392). Que se presuponga contrafácticamente en el actuar comunicativo esa comunidad ideal no significa que sean accesibles a los interlocutores sus precisos perfiles como término con el que comparar o medir un discurso o el acuerdo real. Lo único que cabe es la realización teórica de un «experimento intelectual», de una «ficción metódica» con la que se comprueba cuáles son en su configuración total e ideal esos presupuesto del entendimiento comunicativo y que, si se dieran plenamente, conllevarían la resolución de todo conflicto sin poder ni violencia y sin derecho (392-393).

Alcanzamos con lo anterior otro de los puntos difíciles de la construcción de Habermas. Esta cuestión del experimento mental plantea la dificultad de entender cómo le es posible al «experimentador» ponerse en el lugar del «observador ideal» si no puede dejar de estar en un determinado contexto que condiciona su comprensión, incluso su comprensión de cuáles pueden ser los presupuesto ideales de la comunicación. Es la pregunta de si no cabe que, por ejemplo, en una sociedad esclavista un sujeto se plantee los presupuestos ideales de la comunicación y los conciba como comunicación entre 
personas, al mismo tiempo que excluye de esa condición de persona, y por tanto de partícipe en la verdadera comunicación, a los esclavos. Y yendo a un problema más actual, podemos plantearnos la compatibilidad de esos presupuestos con la existencia de fronteras nacionales, que el propio Habermas asume. ¿No supone la configuración de la sociedad ideal en la que los presupuestos de la comunicación se realicen plenamente, con su necesario alcance universalista, una sociedad sin Estados, sin fronteras, un solo ordenamiento jurídico y no ordenamientos que, por distintos, pueden estar enfrentados? En esa sociedad ideal el único medio de «autoorganización» es «el entendimiento discursivo», «sin la adición de la política y el derecho» (393). Y si el derecho existe en nuestras sociedades por causa de que no es posible ese pleno entendimiento como dirimente de los conflictos, ¿hasta qué punto tiene sentido y no es contradictorio entender que el derecho se legitima discursivamente, que puede ser fuerza legítima por estar discursivamente consentidos sus contenidos? De darse ese acuerdo ¿no sería superfluo el derecho? Si el derecho existe porque ese entendimiento perfecto no es alcanzable, ¿cómo puede ser el mecanismo legitimatorio del derecho un entendimiento que no es posible y que, precisamente por no serlo, justifica la existencia del derecho? ¿Tiene sentido legitimar el derecho mediante la remisión a una pretensión cuya imposibilidad explica la existencia misma de lo jurídico ${ }^{2}$ ?

Habermas hace constar que ese experimento mental no puede privar al discurso de su «situatividad en contextos del mundo de la vida» (393). Parece que afirma que las normas, formas de vida, etc., operantes en una sociedad no se pueden equiparar a compulsiones o fuerza, desde el momento en que pueden cuestionarse expresamente en su validez y dejan operar así un discurso capaz de trascenderlas. ¿Pero hasta qué punto ese cuestionamiento posible no es también inmanente a una forma de vida u organización que hace uso de él no para trascenderse, sino como una forma de perpetuarse jugando ese

${ }^{2}$ Nuevamente trata Habermas de salir del dilema mediante la síntesis de los contrarios: ninguna sociedad compleja puede, ni bajo las condiciones más favorables, realizar el modelo de la pura socialización comunicativa, exenta de coacción, es decir, corresponderse plenamente con los presupuestos o condiciones de posibilidad de la comunicación que hace toda sociedad posible. Pero, en cuanto ese modelo idealmente presupuesto contiene la idea de una sociedad perfectamente autoorganizada, sin poder ni derecho, sus caracteres se proyectan en la sociedad democrática bajo la forma de un derecho que «incorpora» aquellos momentos de socialización comunicativa (396-397). ¿No es esto como hablar de un derecho que incorpora el no derecho o de la institucionalización bajo forma jurídica y, por tanto, coactiva, de un modo de entendimiento que excluye la coacción y que sólo podría darse con plenitud allí donde el derecho no existiera? 
juego, que es su juego, y no el juego de una razón abstracta, universal, intemporal o necesaria?

La importancia de la democracia conlleva el importante papel que Habermas asigna también a las ideas de esfera política pública ${ }^{3}$ y sociedad civil $^{4}$, a fin de que sistemas funcionales como la economía o el poder administrativo no se apropien de los mecanismos de dirección política de la comunidad, sino que sigan sometidos a la voluntad social que se expresa en el derecho. Desde la sociedad civil la percepción y las opiniones sociales se proyectan sobre la esfera pública y en ésta se condensan como opiniones que buscan cauce político e influyen en la formación de la voluntad política mediante los procedimiento democráticos. $\mathrm{Y}$ en ciertos momentos de crisis y transformación social el último recurso como modo de expresión frente al orden establecido y manifestación de la necesidad de nuevos pasos hacia una mejor realización de los derechos, consiste en actos de desobediencia civil. Esta se justifica «sobre la base de un entendimiento dinámico de la Constitución como proyecto inacabado» (464). El mismo Estado de Derecho, para Habermas, es un proceso, siempre necesitado de revisión, para interpretar y realizar cada vez más perfectamente, bajo nuevas circunstancias, el sistema de derechos. Y también las constituciones llevan en su misma esencia la tensión entre el componente moral y universalista que basa la legitimidad de todo derecho, y su concreta ubicación en una época y una sociedad dadas: «las constituciones históricas se pueden entender como interpretaciones de una y la misma praxis -la praxis de autodeterminación de ciudadanos libres e iguales; pero, como toda praxis, también ésta se halla situada en la historia» (467).

Culmina Habermas su obra describiendo el nuevo paradigma jurídico que con su teoría se propone. Entiende por paradigmas jurídicos distintos modos de realizarse el sistema de derechos y los principios del Estado de Derecho. Un paradigma jurídico explica «de qué manera se conciben y se deben tratar los principios del Estado de Derecho y los derechos fundamentales a fin de que puedan cumplir, en un contexto dado, la función que normativamente se les adscribe» (238). Dentro de un paradigma jurídico compartido en una sociedad, el juez se ve descargado de una parte de las decisiones de

${ }^{3}$ «Un entramado de comunicaciones de contenidos y posturas, es decir, de opiniones», en el cual «los flujos de comunicación son filtrados y sintetizados de tal modo que se condensan como opiniones publicas engarzadas por temas especificos» (436).

${ }^{4}$ «La sociedad civil se compone de aquellas asociaciones, organizaciones y movimientos más o menos espontáneamente surgidos y que asumen, condensan y proyectan con eco reforzado sobre la esfera política pública la resonancia que los problemas sociales encuentran en los ámbitos de la vida privada» (444). 
fondo y aumenta la previsibilidad para las partes. En el derecho formal burgués y el del derecho materializado, propio del Estado social. Frente a ellos, Habermas propone el paradigma jurídico procedimental o discursivo. El paradigma liberal adolece de descuidar las condiciones que hacen viable la autonomía privada. Esas condiciones las atiende el paradigma del derecho material, que busca condiciones de justicia social aptas para asegurar los mínimos vitales requeridos para un ejercicio efectivo de la autonomía por los sujetos. Pero este paradigma tiene, a su vez, los defectos del paternalismo, pues desactiva la esfera política mediante medidas que surten un efecto desmotivador de la participación y disolutivo de las interrelaciones sociales.

El paradigma procedimental resalta la interrelación ineludible entre autonomía pública y privada: sólo sobre la base de la autonomía privada es posible la autonomía pública de los individuos, la autoorganización social; a su vez, sólo ese autogobierno pone las condiciones para que cada cual pueda ser privadamente autónomo. «El derecho legítimo -dice Habermas- cierra el círculo entre, por un lado la autonomía privada de sus destinatarios, tratados de modo igual, y, por otro, la autonomía pública de los ciudadanos que, como autores con igual derecho del ordenamiento jurídico, han de decidir (en última instancia) sobre los criterios de la igualdad de trato» (500). Intenta Habermas con su nuevo paradigma salvar los otros dos paradigmas, el liberal y el del derecho material. «Un programa jurídico se muestra como discriminatorio cuando es insensible frente a las consecuencias limitadoras de la libertad que tienen las desigualdades fácticas; es paternalista cuando es insensible frente a las consecuencias limitadoras de la libertad que conlleva la compensación estatal de aquellas desigualdades» (503).

Finaliza afirmando que el paradigma comunicativo del derecho no prejuzga un modelo determinado de sociedad o de vida buena y queda sometido a discusión, bajo las condiciones que él mismo establece. Únicamente su núcleo es dogmático: «la idea de autonomía, conforme a la cual los seres humanos sólo actúan como sujetos libres en la medida en que sólo obedecen aquellas leyes que se han dado a sí mismos según ideas intersubjetivamente adoptadas». Concluye la obra con esta frase: «en esta idea se expresa una tensión entre facticidad y validez, tensión que viene «dada» con el dato de la constitución lingüística de las formas de vida socio-culturales, es decir, que es irrebasable para nosotros que hemos formado nuestra identidad en una tal forma de vida» (537). Acaba, pues, el trabajo con un nuevo intento de salida para los dilemas a que hemos venido aludiendo: entre lo fundado para nosotros y lo fundado en general o en absoluto puede no haber coincidencia; pero, si se permite el juego de palabras, para nosotros lo fundado es lo fundado para nosotros. 
No podemos conocer ni concebir otra cosa. Por eso las tesis de Habermas que acabamos de ver tal vez hayan de entenderse, más que como fundamentación del derecho, o del derecho moderno, como reconstrucción (tal como él mismo afirma en algún momento) del fundamento que se presupone en el derecho moderno y en la sociedad que lo ha originado. El problema que permanece es el de cómo conciliar, por un lado el cognitivismo general de Habermas y el apoyo de su teoría del discurso en los presupuestos inmanentes al uso del lenguaje en todo tiempo y lugar, con, por otro lado, el circunscribir la aplicación de esos postulados a un derecho moderno cuya racionalidad por esa vía se postula. 